\title{
Eye Tracking Usability Testing Using User-Centered Design Analysis Method
}

\author{
${\text { Khafidurrohman } \text { Agustianto }^{1 *} \text {, Adi Heru Utomo }}^{2}$, Ratih Ayuninghemi ${ }^{3}$, Prawidya \\ Destarianto $^{4}$, I Gede Wiryawan ${ }^{5}$, Ely Mulyadi ${ }^{6}$ \\ 1, 2, 3, 4, 5, 6 Information Technology Department, Politeknik Negeri Jember, Indonesia \\ "Corresponding author. Email: agustianto.khafid@gmail.com
}

\begin{abstract}
The interaction between humans and computers has entered a new phase, where modern humans can no longer be separated from computers in their daily lives. This interaction raises a new topic of discussion, namely HumanComputer Interaction (HCI). $\mathrm{HCI}$ is the intersection of cultural, social, cognitive, and aesthetic with computing and information technology. It covers a large number of problems, theories, technologies, designs, tools, environments, and human experiences in knowledge work, leisure and leisure activities, teaching and learning, and the anthology of everyday life. This study aimed to develop Eye Tracking Usability Testing System Development Using User-Centered Design Analysis Method. This study used a Tobii Eye Tracking sensor which was extracted and used as input to the GOM method. The results of this study were applications that could analyze the quality of interaction from users to website applications with a reading accuracy rate of $88 \%$, especially in service applications, so that they could be used to make application improvements to improve services.
\end{abstract}

Keywords: $H C I$, eye tracking, UX, usability

\section{INTRODUCTION}

The interaction between humans and computers has entered a new phase, where modern humans can no longer be separated from computers in their daily lives. This interaction raises a new topic of discussion, namely Human-Computer Interaction (HCI). $\mathrm{HCI}$ is the intersection of cultural, social, cognitive, and aesthetic with computing and information technology. It covers a large number of problems, theories, technologies, designs, tools, environments, and human experiences in knowledge work, leisure and leisure activities, teaching and learning, and the anthology of everyday life [1]. Observations made by Researchers at the Line (Combined Research) in Information Systems (IS) in the Information Technology Department, as well as one of the pioneers of TEFA from the Information Technology Department, found that the interaction between humans and computers developed rapidly during this pandemic in the Jember State Polytechnic environment.

This development is marked by several processes being replaced by applications, both WEB-based (the majority) and Mobile-based applications. This condition is of course also found in institutions and also industry, so this condition causes problems related to the quality of applications, especially those used to provide services. The quality of the application can be reflected in the user experience (UX) [2], so this phenomenon is captured by researchers in the field of IS to develop service products to measure UX through non-tax revenues (PNBP) funding which will then become the flagship product of the TEFA JTI Innovation pilot, Information Technology Department. Several studies related to UX were conducted by [3][4][5], and focused on UX analysis on websites, while research [6] on graphics-based applications and research [7][8][9] used an intelligent approach to perform UX analysis.

This study aimed to develop Eye Tracking Usability Testing System Development Using User-Centered Design Analysis Method. The research was under the RIR of Politeknik Negeri Jember 2021-2025, especially in the Informatics Engineering Study Program, Development of Artificial Intelligence-Based Systems, namely Simulation, HCI, Digital Image Processing, and Computer Vision (RIR Polije page 137). This study resulted in a tool with a TKT of 6 under the PNBP 
Manual. This research was also in line with the products developed at TEFA JTI Innovation, Department of Information Technology, especially in the Usability Analysis Application product line. This study used a Tobii Eye Tracking sensor which was extracted and used as input to the GOM method. This study followed research [10][11][12] which focused on UX assessment on web-based service applications. The result of this study was a product/application that could analyze the quality of interaction from the user/user to the application, especially service applications so that it could be used to make application improvements to improve services. Seeing from the benefits obtained from this research tool, this tool is expected to be the flagship product of TEFA JTI Innovation, Department of Information Technology, especially in the Usability Analysis Application product line.

\section{RELATED WORKS}

The quality of the application can be reflected in the user experience (UX) [2], so this phenomenon is captured by researchers in the field of IS to develop service products to measure UX through non-tax revenues (PNBP) funding which become the flagship product of the TEFA JTI Innovation pilot, Information Technology Department. Several studies related to UX were conducted by [3][4][5]. This research focused on UX analysis on websites, while research [6] on graphics-based applications and research [7][8][9] used an intelligent approach. This study took the research gap on the implementation of eye movement as a variable for analyzing the UX quality of the application because the eye is one of the pointing devices, as one of the "tools" that shows where our attention is directed [13].

This study aimed to develop Eye Tracking Usability Testing System Development Using User-Centered Design Analysis Method. It used a Tobii Eye Tracking sensor which was extracted and used as input to the GOM method. This study followed research [10][11] which focused on UX assessment on web-based service applications. The result of this study was a product/application that could analyze the quality of interaction from the user/users to the application, especially service applications so that it can be used to make application improvements to improve services. Seeing from the benefits obtained from this research tool, this tool is projected to be the flagship product of TEFA JTI Innovation, Department of Information Technology, especially in the Usability Analysis Application product line.

The design of the tool developed by the research is shown in Figure 1, where the sensor was placed at the bottom of the device screen, then the user operated the app being assessed. The result Log "eyes" from the user was translated by the machine/ artificial intelligence to be given a UX value from the user. In a wider application, this tool can also be used for advertising and film research, so the potential results of this research can be used as research products as the leading products of TEFA JTI Innovation, Department of Information Technology.

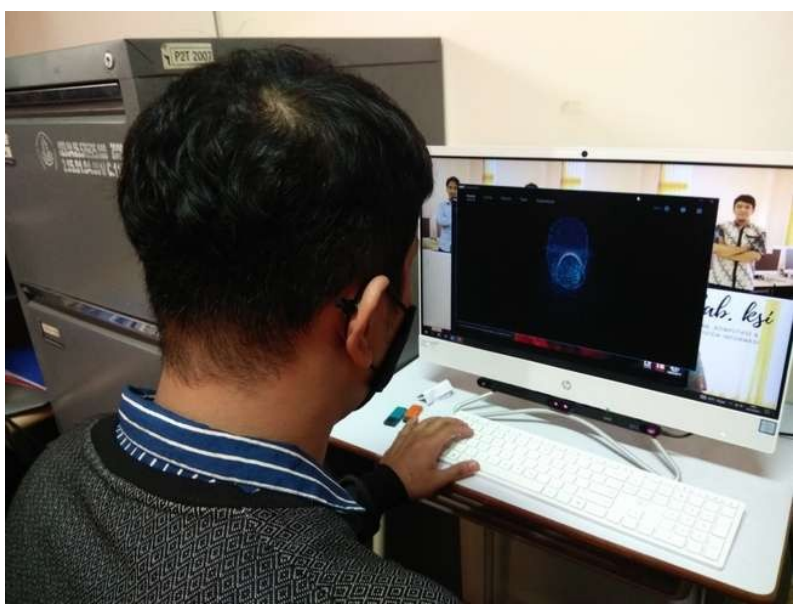

Figure 1 Eye Tracking Device

\section{RESEARCH METHOD}

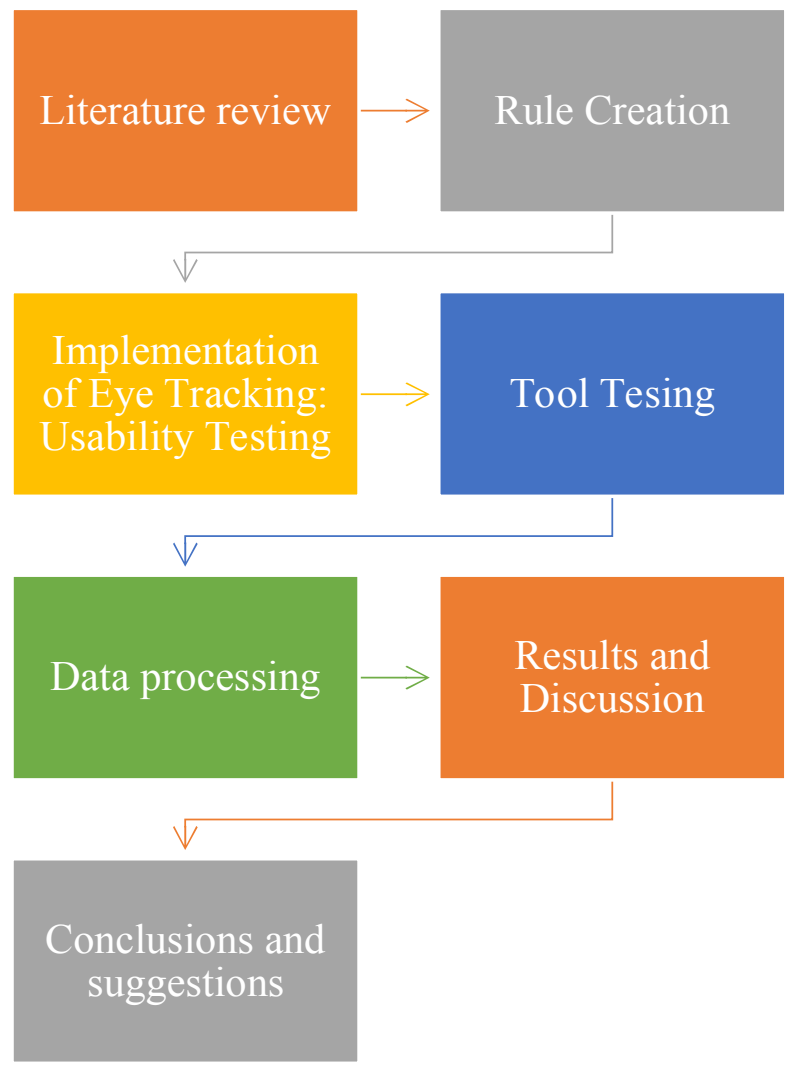

Figure 2 Research Method 
Literature study based on Figure 2, was carried out to collect information from several references related to the problems to be discussed. Theories related to the problems to be researched were used as the basis for data processing. At this stage, the state of the art (research position) was obtained. The literature study that had been carried out showed that there was a need that had not been achieved. So in this position, identification and resolution of problems that became the objectives of the study were carried out.

Rule creation was an important step in this research because, in this study, it used an eye sensor/eyetracking, which read the user's eye movements when interacting/using the application, to then be distinguished in the UX class. The rules obtained were then implemented into Eye Tracking Usability Testing and this was done using the UCD: GOM approach.
Table 1. Testing results

\begin{tabular}{|l|l|l|l|l|}
\hline & Task 1 & Task 2 & Task 3 & Task 4 \\
\hline Web A & 4,873 & 3,082 & 5,769 & 8,029 \\
\hline Web B & 3,564 & 1,813 & 3,913 & 4,017 \\
\hline Difference & 1,309 & 2,390 & 2,229 & 4,012 \\
\hline
\end{tabular}

\begin{tabular}{|l|l|l|l|l|}
\hline & Task 5 & Task 6 & Task 7 & Task 8 \\
\hline Web A & 10,115 & 8,070 & 9,043 & 8,871 \\
\hline Web B & 3,593 & 4,309 & 11,032 & 10,924 \\
\hline Difference & 6,522 & 3,761 & 1,989 & 2,053 \\
\hline
\end{tabular}

similar studies that might find results that can improve the reading/modeling of the system.

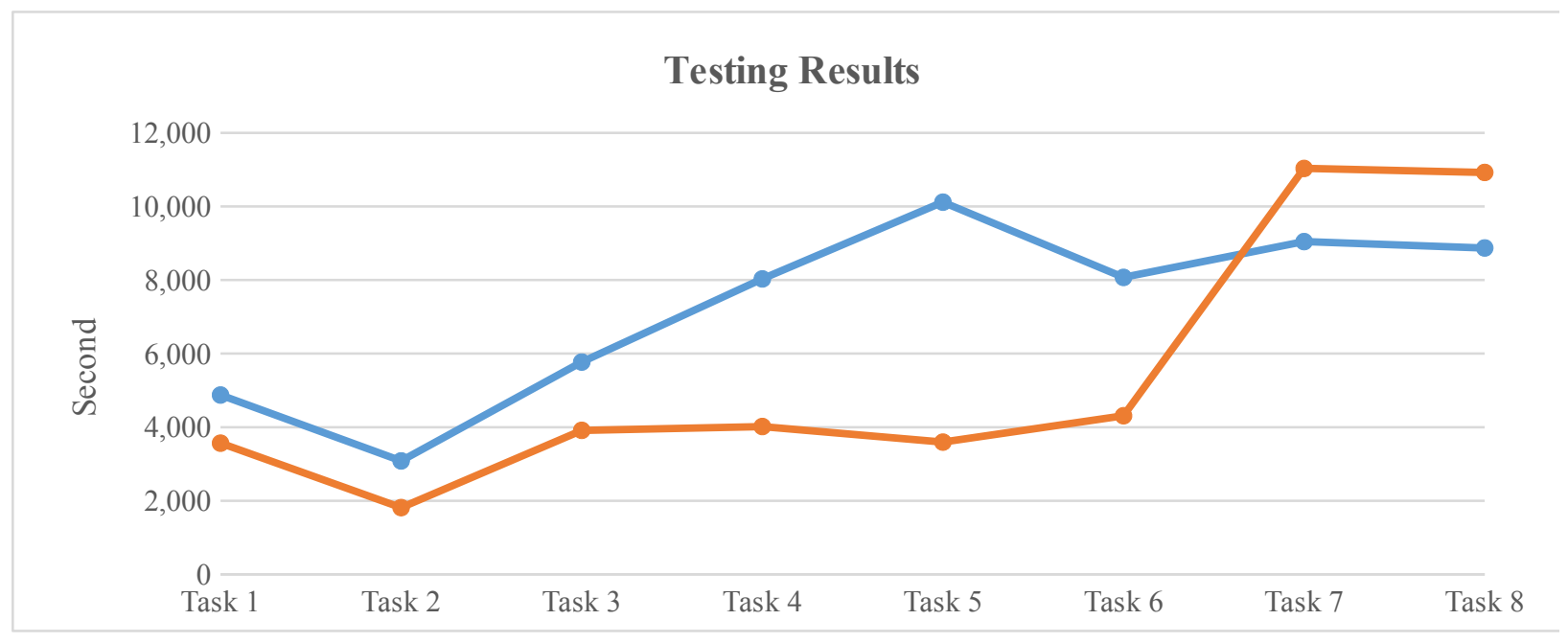

Figure 3. Testing results

The use of the UCD: GOM method aimed to produce more accurate readings. At this stage, a trial was carried out to prove that the sensor readings were appropriate. The accuracy of the tool was also obtained.

The data from the test results were then obtained. This processing aimed to evaluate the use of the Backpropagation Neural Network algorithm which was implemented as a result of reading user logs. The results of data processing in the form of tool accuracy were then compared with manual calculations, to test the accuracy by ground truth. The results obtained at this stage discussed the factors that affected the accuracy value obtained. The last stage of the research was to draw conclusions from the results of the analysis of the discussion and provide suggestions for further research. This section also reviewed the application of related technology/research. It was done to ensure the research had a clear/novelty contribution to the world of research. In addition, by continuing to review research developments, this study can be beneficial if there are

\section{RESULTS AND DISCUSSION}

Data analysis was carried out by adding up the fixation time before the respondent succeeded in doing the task on the problem by scanning the coordinate data shown by Table 1 and Figure 3, and then making conditions if the coordinate value was greater than the value of $\mathrm{x} 1$ or the value of $\mathrm{y} 1$ and the smaller value was equal to the value of $\mathrm{x} 2$ or the value of $\mathrm{y} 2$, then the value was 1 , otherwise, the value is 0 . The time of the coordinates was added up to the coordinates that were worth 1 the first time and then was displayed on the average page.

The following was "if condition" codes to determine whether the coordinates had entered the range on the tested feature button.

if ( $\$$ content ['acr_x']>=\$content[' $x 1$ '] $\& \&$ $\$$ content ['acr_x']<=\$content ['x2']) $\& \&$ 
( $\$$ content ['acr_y'] >=\$content ['y1'] $\& \&$ \$content [ 'acr_y'] $<=\$$ content [ 'y2'] )) \{

\$upd = mysqli_query $(\$ d b$, "UPDATE act_coordinate SET acr_status $=1$ WHERE acr_id = \$content [acr_id] ") ;

At this stage, there was coordinate data that did not enter the range of the buttons on the question, which was marked with a red print. This was due to the inaccuracy of the tool, as well as the sitting position of each respondent that was still not following the tool. The slope of the laptop screen also determined the tilt of the tool because the tool was attached to the bottom of the laptop screen. So, there were data that did not enter the range of buttons on the question even though the respondent's eyes had seen the question. However, the tools and systems recorded different coordinates because the tools were not yet accurate.

Therefore, each respondent must first calibrate and it was assumed that the tool could be more accurate and record the coordinates according to what was seen by the user. In contrast to Areas Of Interest (AOI), there were three different conditions because there were 3 AOIs registered. First, if the coordinate value was greater than the value of $\mathrm{x} 1$ and $\mathrm{y} 1$ in Area 1 and smaller was the same as the value of $x 2$ and y2 in Area 1 , it meant that the coordinates were entered in Area 1. Second, if the coordinate value was greater than the value of $\mathrm{x} 1$ and $\mathrm{y} 1$ in Area 1. Area 2 and smaller were equal to the values of $\mathrm{x} 2$ and $\mathrm{y} 2$ in Area 1, meaning that the coordinates were entered in Area 2. Third, if the larger coordinate values were the same as the values of $\mathrm{x} 1$ and $\mathrm{y} 1$ in Area 3 and smaller were the same as the values of $\mathrm{x} 2$ and $\mathrm{y} 2$ in Area 1, it meant that the coordinates were entered in Area 3. The number of fixations for each area was added and the average value was searched, then displayed on the AOI page.

The following was the "if condition" code to determine whether the coordinates entered Area 1, Area 2, or Area 3.

if ( $\$$ content [ 'acr_x']>=\$i_aoi[' $\left.x 1^{\prime}\right]$ $\& \&$ \$content [' $\left.\mathrm{acr} \overline{\mathrm{x}} \mathbf{\prime}^{\prime}\right]<=\$ i$ aoi [' $\left.\mathrm{x} 2^{\prime}\right] \& \&$ $\$$ content ['acr y'] $>=\$ i$ ao $\bar{i}\left[{ }^{\prime} y 1{ }^{\prime}\right] \& \&$ \$content [ 'acr_y'] $<=\$ i_{-}$aoi [ 'y2 '] ) \{

\$upd = mysqli query $(\$ d b$, "UPDATE act_coordinate SET acr status = '\$i_aoi[area_id]' WHERE $\bar{E}$ acr_id = \$content[acr_id]");

After getting test data from the currently used WEB display and the new WEB, the researchers found the results that were shown in Tabel 1 and Figure 3. After calibrating each respondent, a blank value on the average still appeared because after the calibration process, at the time of data collection, the respondent was still moving around in a sitting position, the tilt of the laptop screen was also changed to adjust the tool to the respondent's eyeball. Average data were shown in the appendix.

From Tabel 1 and Figure 3, it could be concluded that the test with the new WEB display in Problem 1 was 1.309 seconds faster than the Old WEB test, Problem 2 was 2.39 faster, Problem 3 was 2.229 faster, Question 4 was 4,012 faster, Question 5 was 6.522 faster, and Question 6 was 3,761 seconds faster on the second test. This was because the position of the menu on the old WEB was in the navbar and when the cursor switched from the menu area, the menu automatically closed and did not display the sub-menu. However, in the new WEB, the menu position was in the sidebar and when the cursor moved from the menu area, the submenu still appeared, making it easier for respondents to find it.

However, in Question 7 (looking for the Change Password feature) and Question 8 (looking for the Log Out feature), the new WEB display took 1,989 seconds longer in Question 7 and 2,053 seconds in Question 8 than the WEB display currently used. It is because, on the display of the new WEB features, Change Password and Log Out features are grouped in the Account menu, while in the old WEB view, these features were not grouped and contained in the navbar so that respondents could find them more easily.

Table 2. Expert results

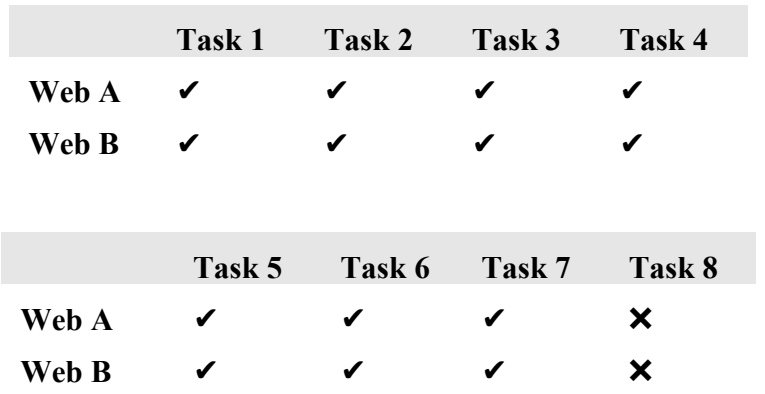

The test results by comparing expert opinions to the readings of the tool (Tobii Eye Tracker) had two different results shown by Tabel 2 and the accuracy produced by the tool was $88 \%$.

\section{CONCLUSION}

Based on the results of the discussion on the analysis and development of the usability test system at the WEB of Polije, it can be concluded that there were several stages in the development of the usability testing system at the Polije WEB, including the determination of the coordinates of the submenu to be tested, calibration of the tool, data collection using the tool, and implementation.

The new WEB test results in Question 1 were 1.309 seconds faster than the old WEB test, Question 2 was 
2.39 seconds faster, Question 3 was 2,229 seconds faster, Question 4 was 4,012 seconds faster, Question 5 was 6,522 seconds faster, and Question 6 was 3,761 seconds faster. However, in Question 7 WEB, the average time was 1,989 seconds longer and in Question 8 , the average time was 2,053 seconds.

The test results were obtained by comparing experts' opinions to the readings of the tool (Tobii Eye Tracker). It had two different results shown in Tabel 2 and the accuracy produced by the tool was $88 \%$.

\section{ACKNOWLEDGMENTS}

The authors would like to acknowledge the financial support of this work by grants from Politeknik Negeri Jember. The authors also thanked P3M and Jurusan Teknologi Informasi, Politeknik Negeri Jember, that provided support and assistance in completing this research.

\section{REFERENCES}

[1] J. S. Dumas and J. E. Fox, Usability Testing: A Practitioner's Guide to Evaluating the User Experience. 2020.

[2] Z. D. Champiri, G. Mujtaba, S. S. Salim, and C. Yong Chong, "User experience and recommender systems," 2019 2nd Int. Conf. Comput. Math. Eng. Technol. iCoMET 2019, pp. 1-5, 2019, doi: 10.1109/ICOMET.2019.8673410.

[3] M. Joo and W. Lee, "WebProfiler: User interaction prediction framework for web applications," IEEE Access, vol. 7, pp. 154946-154958, 2019, doi: 10.1109/ACCESS.2019.2949077.

[4] H. Z. Jahromi, D. T. Delaney, and A. Hines, "Beyond First Impressions: Estimating Quality of Experience for Interactive Web Applications," IEEE Access, vol. 8, pp. 47741-47755, 2020, doi: 10.1109/ACCESS.2020.2979385.

[5] Krisnawati, M. Hayaty, B. Setiaji, and A. Setyanto, "First-time user experience assessment on web based online examination," 2019 Int. Conf. Inf. Commun. Technol. ICOIACT 2019, pp. 829-834, 2019 , doi: 10.1109/ICOIACT46704.2019.8938550.

[6] A. Oulasvirta, N. R. Dayama, M. Shiripour, M. John, and A. Karrenbauer, "Combinatorial Optimization of Graphical User Interface Designs," Proc. IEEE, vol. 108, no. 3, pp. 434464, 2020, doi: 10.1109/JPROC.2020.2969687.

[7] K. Bouraqia, E. Sabir, M. Sadik, and L. Ladid, "Quality of Experience for Streaming Services: Measurements, Challenges and Insights," IEEE Access, vol. 8, pp. 13341-13361, 2020, doi:
10.1109/ACCESS.2020.2965099.

[8] S. V. Aciar and M. Ochs, "Classifying user experience based on the intention to communicate," IEEE Lat. Am. Trans., vol. 18, no. 8, 2020, pp. 1337-1344, doi: 10.1109/TLA.2020.9111668.

[9] K. E. S. Souza, M. C. R. Seruffo, H. D. De Mello, D. D. S. Souza, and M. M. B. R. Vellasco, "User Experience Evaluation Using Mouse Tracking and Artificial Intelligence," IEEE Access, vol. 7, pp. 96506-96515, 2019, doi: 10.1109/ACCESS.2019.2927860.

[10] J. DIaz et al., "Website Transformation of a Latin American Airline: Effects of Cultural Aspects and User Experience on Business Performance," IEEE Lat. Am. Trans., vol. 17, no. 5, pp. 766-774, 2019, doi: 10.1109/TLA.2019.8891945.

[11] T. Van Der Geest, J. Ramey, S. Rosenbaum, and L. Van Velsen, "Introduction to the special section: Designing a better user experience for self-service systems," IEEE Trans. Prof. Commun., vol. 56, no. 2, pp. 92-96, 2013, doi: 10.1109/TPC.2013.2258731.

[12] K. Agustianto, P. Destarianto, and W. K. Dewanto, "Development of real-time motion autonomous surface vehicle controlling for coral reef conservation and fisheries," in IOP Conference Series: Earth and Environmental Science, 2020, vol. 411, no. 1, doi: 10.1088/1755$1315 / 411 / 1 / 012060$

[13] S. Wibirama, "Eye tracking — sebuah perjalanan | Sunu Wibirama." https://sunu.staff.ugm.ac.id/2014/02/21/eyetracking-sebuah-perjalanan/ (accessed Apr. 09, 2021). 